\title{
Nutritional Status among Females of Bhaina Tribe of Bilaspur, Chhattisgarh, India: An Anthropological Insight
}

\author{
Huidrom Suraj Singh, Manisha Ghritlahre, and Subal Das \\ Department of Anthropology and Tribal Development, Guru Ghasidas Vishwavidyalaya (Central University), Bilaspur, \\ Chhattisgarh 495009, India \\ Correspondence should be addressed to Subal Das; das_vu@rediffmail.com
}

Received 28 May 2014; Accepted 3 September 2014; Published 23 September 2014

Academic Editor: Tetsuo Katsuura

Copyright (C) 2014 Huidrom Suraj Singh et al. This is an open access article distributed under the Creative Commons Attribution License, which permits unrestricted use, distribution, and reproduction in any medium, provided the original work is properly cited.

\begin{abstract}
Problem of malnutrition increases, being one of the significant national issues in a developing country like India. In the present study, an attempt was made to understand the sociodemographic profile and nutritional status among the Bhaina tribes of Bilaspur, Chhattisgarh. A total of 161 females (2-75 years) were screened for anthropometric measurements. Nutritional status was evaluated in four groups of female categories: preschool: $2-5$ years $(n=11)$, children: $6 \# \mathrm{x} 2013 ; 12$ years $(n=28)$, adolescent: $13-18$ years $(n=22)$, and adults $>18$ years $(n=100)$ using the age specific cutoff points of body mass index (BMI). Statistical analysis was performed using MS EXCEL and SPSS software. More than $30 \%$ of the studied population is observed to be illiterate and unemployed. Significant age group difference is observed for anthropometric variables considered in the present study. Overall prevalence of thinness among the studied population was 32.3\% (critical). Occurrence of thinness was found to be highest among children (57.1\%). Occupation with wage labourer is significantly higher among parents of normal children (26.6\%) than parents of undernourished children (19.6\%). Findings of the present study suggest significance of anthropological approach in understanding nutritional status among different ethnic groups, specifically tribal community.
\end{abstract}

\section{Introduction}

Understanding variation/distribution of nutritional status in terms of malnutrition/undernutrition (a deficiency of calories or of one or more essential nutrients) among nutritionally vulnerable populations is very essential in developing countries like India, accounting highest occurrence of childhood malnutrition in the world [1]. Moreover, this is expected to be higher among lower socioeconomic sections of the country, specifically the tribal community.

Chhattisgarh, newly formed state, is home for 42 different tribes including five primitive tribe groups (PTGs) comprising about 12 lakh tribal families accounting $>30 \%$ of the total population of the state [2]. Majority of them are living below poverty line (BPL), living in rural and remote areas, and working as "agricultural labourers." The Bhaina tribe is one of the ancient tribes found principally in the Bilaspur District, Chhattisgarh [3]. They are concentrated in Central Province and considered as one of the oldest residents of the country besides Gond and Kawar tribe. In terms of its origin, anthropologists argue that Bhaina is descendent of other tribes of Indian Territory. Literature shows that the term Bhaina have been derived from the Baiga tribe, a primitive Dravidian family, whose home is on the Eastern Satpura Hills [4]. The Baiga, the name, means a sorcerer of medicine man. The Bhaina Baiga tribe is divided into a number of endogamous groups "jat" based on the distribution in different regions such as Dudh Bhaina, Kath Bhaina, and Raj or Rai Bhaina. The Bhainas of Bilaspur are probably offshoot of Kath Bhaina $[4,5]$, though the Bhainas no longer admit identity with the Baigas [4]. Recently they have gained the status of being one of the scheduled tribes of India.

The social organization of this community attracts mind of anthropologists from different parts of the world in terms of their social customs, marriage practices, religious and superstitions, admission of outsiders and offences, and specifically belief/practice of totemism. Sir, James G Frazer wrote in 
TABLE 1: Definitions of anthropometric variables used in the present study.

\begin{tabular}{ll}
\hline Measurement & Definition \\
\hline Maximum head length (g-op) & $\begin{array}{l}\text { It measures the straight distance between glabella (g) and opisthocranion } \\
\text { (op), that is, the most projecting point on the dorsal surface of the head in the } \\
\text { midsagittal plane }\end{array}$ \\
\hline $\begin{array}{l}\text { Maximum head breadth (eu-eu) } \\
\text { Nasal breadth (al-al) }\end{array}$ & $\begin{array}{l}\text { It measures the straight distance between the two Eurya, that is, maximum } \\
\text { breadths taken at right angle to midsagittal plane wherever found }\end{array}$ \\
\hline Nasal height (n-sn) & $\begin{array}{l}\text { It measures the straight distance between the two Alaria (al), that is, the most } \\
\text { laterally placed points on the nasal wings }\end{array}$ \\
$\begin{array}{l}\text { Morphological facial height/total facial } \\
\text { height (n-gn) }\end{array}$ & It measures the straight distance between nasion (n) and subnasale (sn) \\
\hline Breadth of bizygomatic arch (zy-zy) & It measures the straight distance between nasion (n) and gnathion (gn) \\
\hline Stature & It measures the straight distance between the two Zygia (z) \\
\hline
\end{tabular}

TABle 2: Age specific cutoff points of BMI described by WHO 1995 [8] and Cole et al. 2000 and 2007 [9, 10].

\begin{tabular}{|c|c|c|c|c|c|c|c|}
\hline \multirow{2}{*}{ Categories } & \multirow{2}{*}{ Age } & \multicolumn{3}{|c|}{ Thinness } & \multirow{2}{*}{$\begin{array}{c}\text { Overweight } \\
(25.0-29.99)\end{array}$} & \multirow{2}{*}{$\begin{array}{l}\text { Obese } \\
(\geq 30)\end{array}$} & \multirow{2}{*}{$\begin{array}{c}\text { Reference } \\
\text { WHO, } 1995 \text { [8] }\end{array}$} \\
\hline & & Grade III $(<16.0)$ & Grade II (16.0-16.9) & Grade I (17.0-18.49) & & & \\
\hline \multirow[t]{4}{*}{ Preschool } & 2 & 13.24 & 13.90 & 14.83 & 18.02 & 19.81 & \\
\hline & 3 & 12.98 & 13.60 & 14.47 & 17.56 & 19.36 & \\
\hline & 4 & 12.73 & 13.34 & 14.19 & 17.28 & 19.15 & \\
\hline & 5 & 12.50 & 13.09 & 13.94 & 17.15 & 19.17 & \\
\hline \multirow[t]{7}{*}{ Children } & 6 & 12.32 & 12.93 & 13.83 & 17.34 & 19.65 & \\
\hline & 7 & 12.26 & 12.91 & 13.86 & 17.75 & 20.51 & \\
\hline & 8 & 12.31 & 13.00 & 14.02 & 18.35 & 21.57 & \\
\hline & 9 & 12.44 & 13.18 & 14.28 & 19.07 & 22.81 & \\
\hline & 10 & 12.64 & 13.43 & 14.61 & 19.86 & 24.11 & Cole et al., 2000, $2007[9,10]$ \\
\hline & 11 & 12.95 & 13.79 & 15.05 & 20.74 & 25.42 & \\
\hline & 12 & 13.39 & 14.28 & 15.62 & 21.68 & 26.67 & \\
\hline \multirow[t]{6}{*}{ Adolescent } & 13 & 13.92 & 14.85 & 16.26 & 22.58 & 27.76 & \\
\hline & 14 & 14.48 & 15.43 & 16.88 & 23.34 & 28.57 & \\
\hline & 15 & 15.01 & 15.98 & 17.45 & 23.94 & 29.11 & \\
\hline & 16 & 15.46 & 16.44 & 17.91 & 24.37 & 29.43 & \\
\hline & 17 & 15.78 & 16.77 & 18.25 & 24.70 & 29.69 & \\
\hline & 18 & 16.00 & 17.00 & 18.50 & 25.00 & 30.00 & \\
\hline
\end{tabular}

his book Totemism and Exogamy about the division of Bhaina tribe into a number of totem clans, named after animals or plants [6], though no information/literature is available on anthropometric data (in terms of nutritional status) of Bhaina tribe. Therefore, an attempt was made to understand the sociodemographic profile and nutritional status with reference to anthropometric variables among the Bhaina tribe of Sadhwani Village (Pendra), Bilaspur, Chhattisgarh.

\section{Materials and Methods}

The present study was conducted among Bhaina community, on a sample size of 302 individuals of which 141 were male and 161 were female (age range: $2-75$ years) in Sadhwani village, Pendra District. It is located $220 \mathrm{~km}$ from Raipur, the capital of Chhattisgarh. Study was carried out from 17th of May 2013 to 28th of May 2013.
Data pertaining to age, sex, occupation, educational status, and marital status were collected from both male and female using a pretested questionnaire by house-tohouse visit following interview and examination. Age of the children was documented from their birth certificates provided by nearest Primary Health Centre (PHC) or polio vaccination card provided by the teachers of Anganwadi and subsequently confirmed from their parents. Age of the subjects was considered to the nearest whole number. Thus, the appropriate (to the nearest whole age) cutoff values were utilized.

Anthropometric measurements including maximum head length, maximum head breadth, nasal breadth, nasal height, morphological facial height, breadth of bizygomatic arch, stature, and body weight were taken from female group only after obtaining prior consent from the subject, parents, village chief, and higher authorities. The anthropometric measurements were defined in Table 1. Anthropometric 
TABLE 3: Socioeconomic profile among Bhaina tribe of Bilaspur.

\begin{tabular}{|c|c|c|c|}
\hline Characteristics & Male (141) & Female (161) & $P$ value \\
\hline Age (years) $($ mean $\pm S D)$ & $29.57 \pm 16.31$ & $26.85 \pm 17.69$ & $1.38(0.168)^{\mathrm{a}}$ \\
\hline \multicolumn{4}{|l|}{ Education } \\
\hline Illiterate & $25(17.73 \%)$ & $69(42.85 \%)$ & \multirow{4}{*}{$23.7(<0.0001)^{b}$} \\
\hline ICDS & $44(31.20 \%)$ & $42(26.08 \%)$ & \\
\hline Primary & $59(41.84 \%)$ & $43(26.71 \%)$ & \\
\hline Secondary & $13(9.22 \%)$ & $7(4.35 \%)$ & \\
\hline \multicolumn{4}{|c|}{$\operatorname{Occupation}^{\dagger}(\mathrm{M}=201 ; \mathrm{F}=201)$} \\
\hline Unemployed & $70(34.82 \%)$ & $64(31.84 \%)$ & \multirow{4}{*}{$111(<0.0001)^{\mathrm{b}}$} \\
\hline Cultivator & $101(50.25 \%)$ & $27(13.43 \%)$ & \\
\hline Wage labour & $25(12.44 \%)$ & $28(13.93 \%)$ & \\
\hline Other* & $5(2.48 \%)$ & $82(40.79 \%)$ & \\
\hline \multicolumn{4}{|l|}{ Marital status } \\
\hline Married & $84(59.57)$ & $93(57.76)$ & \multirow{2}{*}{$0.102(0.750)^{\mathrm{b}}$} \\
\hline Unmarried & $57(40.42)$ & $68(42.23)$ & \\
\hline
\end{tabular}

${ }^{a}$ Unpaired $t$-test; ${ }^{b}$ likelihood ratio $\chi^{2}$ test $\left(P\right.$ value); ${ }^{\dagger}$ it includes family members who work outside the village; ${ }^{*}$ it includes occupation such as business (in male population) and housewife (in female population).

ICDS: Integrated Child Development Programme.

TABLE 4: Anthropometric measurements and its derived variables among Bhaina tribe of Bilaspur.

\begin{tabular}{|c|c|c|c|}
\hline \multirow{2}{*}{ Variables } & \multicolumn{2}{|c|}{ Female } & \multirow{2}{*}{ Classification } \\
\hline & Mean \pm SD & Range & \\
\hline Maximum head length & $18.29 \pm 0.53$ & $17.00-19.50$ & Long \\
\hline Maximum head breadth & $12.49 \pm 0.52$ & $11.50-13.50$ & Very narrow \\
\hline Nasal height & $4.22 \pm 0.22$ & $03.80-04.70$ & - \\
\hline Nasal breadth & $3.70 \pm 0.16$ & $03.30-04.00$ & Above medium \\
\hline Morphological facial height & $10.42 \pm 0.51$ & $09.40-12.20$ & Low \\
\hline Breadth of bizygomatic arch & $12.63 \pm 0.53$ & $10.10-13.50$ & Narrow \\
\hline \multicolumn{4}{|l|}{ Derived variables } \\
\hline Cephalic index (CI) & $68.35 \pm 3.43$ & $61.50-75.00$ & Hyperdolichocephalic \\
\hline Nasal index (NI) & $87.72 \pm 5.28$ & $75.56-97.56$ & Chamaerhinae \\
\hline Facial index $(\mathrm{FI})$ & $82.62 \pm 4.95$ & 70.37-99.01 & Mesoprosopic \\
\hline
\end{tabular}

indices used in the present study were calculated as follows: morphological facial index $=$ (morphological facial height/breadth of bizygomatic arch $) \times 100$; nasal index $=$ (nasal breadth/nasal height) $\times 100$; and cephalic index $=$ (maximum head breadth/maximum head length) $\times$ 100 [7]. Anthropometric measurements and its derived anthropometric indices were analysed only on adult female group (age $>35$ years).

Females were categorized into four groups, namely, preschool: $2-5$ years $(n=11)$, children: $6-12$ years $(n=28)$, adolescent: $13-18$ years $(n=22)$, and adults $>18$ years $(n=$ $100)$. For assessing nutritional status, body mass index (BMI) was computed following internationally accepted standard equation as $\mathrm{BMI}=$ weight $(\mathrm{kg}) /$ height $\left(\mathrm{m}^{2}\right)$. Nutritional status was evaluated in all the female categories using the age specific cutoff points of BMI described in Table 2. Chronic energy deficiency (CED) Grades III, II, and I of thinness refer to severe, moderate, and mild undernutrition, respectively. Statistical analysis was performed using MS EXCEL and SPSS software (15.0 Version). Statistical significance was set at $P<$ 0.05 .

\section{Results and Discussion}

Sex ratio of a population is usually expressed as the number of females per 1000 males. The overall sex ratio of the sample population is 1142 . Age group of 2-6 years and 7-12 years has highest sex ratio of 2600 and 2600, respectively. The lowest sex ratio was observed among the age group of 13-18 years with 880 . Such low sex ratio among this age group is mainly due to the early age at marriage among the studied population. While comparing educational status, male and female show significant difference in distribution of educational status $(P<0.0001)$. More than $30 \%$ of the studied population is observed to be illiterate among them males constitute $17.7 \%$ and females constitute $42.9 \%$. Proportion of female population goes on decrease when moving towards higher educational status. More than $30 \%$ of 


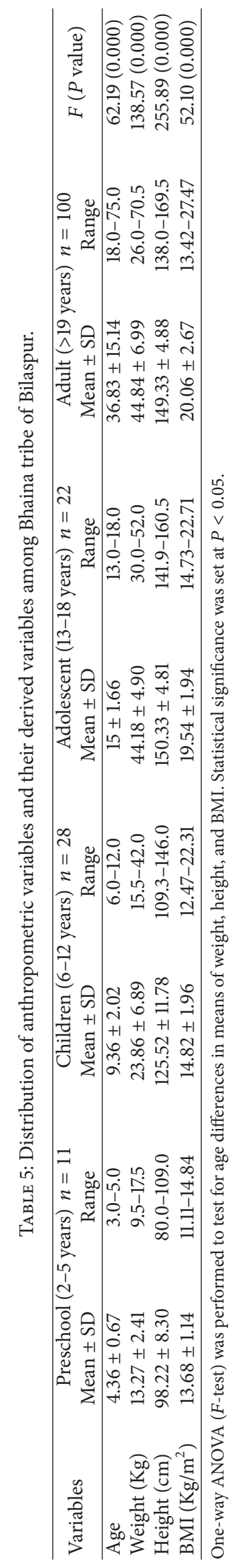


TABLE 6: Occurrence of different BMI categories by age specific cutoff point among Bhaina tribe of Bilaspur.

\begin{tabular}{|c|c|c|c|c|c|c|c|c|}
\hline \multirow{2}{*}{ BMI categories } & \multicolumn{2}{|c|}{ Preschool ( $2-5$ years) $n=11$} & \multicolumn{2}{|c|}{ Children (6-12 years) $n=28$} & \multicolumn{2}{|c|}{ Adolescent (13-18 years) $n=22$} & \multicolumn{2}{|c|}{ Adult ( $>19$ years) $n=100$} \\
\hline & $N$ & $\%$ & $N$ & $\%$ & $N$ & $\%$ & $N$ & $\%$ \\
\hline \multicolumn{9}{|l|}{ Thinness } \\
\hline Grade I & 2 & 18.18 & 14 & 50.00 & 3 & 13.64 & 15 & 15.00 \\
\hline Grade II & 1 & 9.09 & 2 & 7.14 & 1 & 4.54 & 10 & 10.00 \\
\hline Grade III & 2 & 18.18 & - & - & - & - & 2 & 2.00 \\
\hline Normal & 6 & 54.54 & 11 & 39.28 & 18 & 81.82 & 73 & 73.00 \\
\hline Overweight & - & - & 1 & 3.57 & - & - & - & - \\
\hline Obese & - & - & - & - & - & - & - & - \\
\hline
\end{tabular}

the studied population is unemployed. Significant difference was observed between male and female with respect to occupational status $(P<0.0001)$. Majority of the males are engaged with cultivations where as both male and female show similar distribution pattern of wage labourer. No significant difference was observed for marital status among male and female of Bhaina tribe $(P=0.750)$ (Table 3$)$.

Somatometric measurements were recorded among females of Bhaina tribe. Skin colour varies from light brown to dark brown and hair colour is black. Head is hyperdolichocephalic with mean CI of 68.35 , though the number of female individuals with dolichocephalic head is significantly higher than brachycephalic (data not shown). Nose is chamaerhinae with above medium breadth. Its mean nasal index is 87.72. Mesorrhine and leptorrhine nose form are also observed in the present studied population with lower frequency. Face is narrow and of low length having mesoprosopic facial index (mean FI: 82.62) (Table 4). The age wise descriptive statistics of anthropometric variables of the females above 2 years of age are shown in Table 5. It has been clear from the table that the mean weight $(\mathrm{Kg})$ and BMI $\left(\mathrm{Kg} / \mathrm{m}^{2}\right)$ of the studied population were gradually increasing with increasing age except height $(\mathrm{cm})$ among adults $(>18$ years) which suddenly decrease after adolescence. Significant age group difference is observed for anthropometric variables considered in the present study $(P<0.05)$.

Occurrence of thinness was found to be highest among the age group of 6-12 years (57.14\%) followed by preschoolers ( $2-5$ years) $45.45 \%$ and adults ( $>18$ years) $27.0 \%$ and the least prevalence of thinness was observed among adolescents (1318 years) $18.18 \%$.

Grade I thinness was highest among children (50.0\%) followed by preschoolers (18.18\%) and adults (15.0\%) and least among adolescents (13.64\%). Similarly, Grade II thinness was observed highest among adults (10.0\%) followed by preschoolers $(9.09 \%)$ and children (7.14\%) and least among adolescents (4.54\%). Similarly, for Grade III the prevalence of thinness was observed highest among preschooler (18.18\%) and least among adults (2.0\%). Overall prevalence of thinness among the studied populations was $32.30 \%$ (critical). However, occurrence of overweight is almost negligible whereas frequency of obese female individual is absolutely nil in the present studied population (Table 6).

To understand any relationship between parents' occupational status and children's nutritional status, comparison was made between parents' occupational status (both mother and father) and categories of nutritional status of children (218 years). Occupation with wage labourer is higher among parents of normal children (26.56\%) than parents of undernourished children (19.56\%). Parents of normal children servicing in government job are found to be $4.46 \%$ whereas it is completely absent among the parents of undernourished children. Moreover, mothers of normal children are more engaged in wage labourer and service job as compared to the mothers of undernourished children. No significant difference was observed with respect to parent's occupation and nutritional status of the children (Table 7).

Malnutrition among preschool children and adolescents became one of the serious public health problems internationally, especially in developing countries [11]. India, developing country, is facing problem of both "malnutrition" and "obesity" like two opposite poles. One end belongs to the lower socioeconomic groups living in rural and remote areas whereas the other opposite end belongs to higher socioeconomic groups living in urban and metropolitan cities. However, difference is observed within the group too due to individual variation (genetic factors) and exposure to different environmental condition or interaction of both.

Poor nutritional status among mothers has significant impact/influence on the child including low birth weight, preterm, nutritional deficiency, higher death rate, and so forth which finally contributes in shaping demographic structure of the population [12]. Moreover, female are reported to be more vulnerable to malnutrition. It is well known and established that undernourished children living with poor socioeconomic status parents are manifested with severe health problems like growth retardation, low IQ, school failure, behavioural problems, and so forth [13-15]. Moreover, present study is in agreement with previous study's report suggesting malnourished children are more likely to grow into thin adults with low BMI [16]. Therefore, high occurrence of thinness may directly or indirectly affect structure of the population leading to higher rate of morbidity and mortality. The present study revealed high rates of thinness among preschoolers (45.45\%) and children (57.14\%), suggesting critical situation of nutritional status among the Bhaina females of Bilaspur. One of the possible explanations for occurrence of high percentage $(32.30 \%)$ of malnutrition among Bhaina females could be lack of proper education among the studied population which further reduces chance 


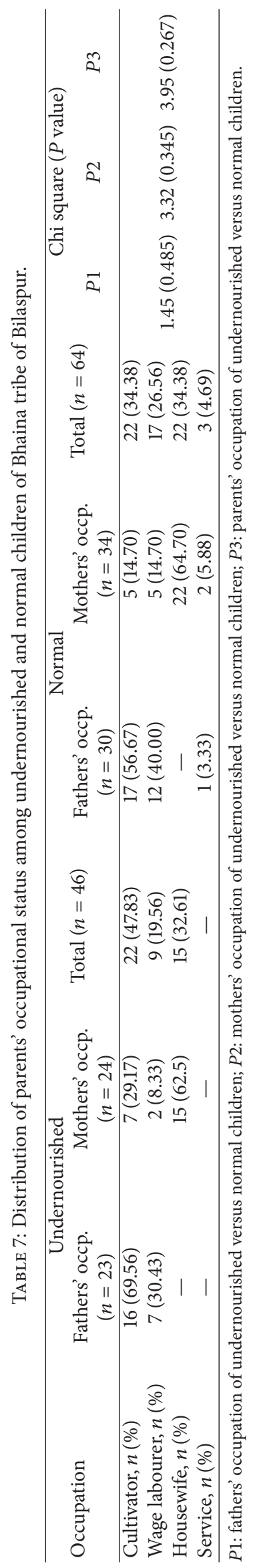


of economic opportunity. Moreover, majority of them are experiencing increasing pressure on their land and working as "farm labourers."

\section{Conclusion}

In brief, findings of the present study suggest significance of studying nutritional status among different ethnic groups, specifically tribal community. Necessary steps should be taken to overcome such issues via recognizing sociocultural practices and beliefs of different tribal community. More precise and detailed studies are required to understand the nutritional status in different age-sex categories with large sample among different tribal groups who are socially and economically backward.

\section{Conflict of Interests}

The authors declare that there is no conflict of interests regarding the publication of this paper.

\section{Acknowledgments}

Authors wish to thank all the Bhaina community who voluntarily participated in the present study.

\section{References}

[1] M. S. Bamji, "Early nutrition and health-Indian perspective," Current Science, vol. 85, no. 8, pp. 1137-1142, 2003.

[2] Census of India, Registrar General and Census Commissioner of India, Government of India, New Delhi, India, 2011.

[3] R. V. Russell, The Tribes and Castes of the Central Provinces of India, vol. 2, Forgotten Books, London, UK, 1916.

[4] P. K. Mohanty, Encyclopaedia of Primitive Tribes in India, vol. I, Gyan Publishing House, New Delhi, India, 2004.

[5] S. T. Das, Life Style, Indian Tribes: Locational Practice, vol. 3, Gyan Publishing House, 1987.

[6] J. G. Frazer, Totemism and Exogamy, Cosimo Inc., 2010.

[7] I. P. Singh and M. K. Bhasin, A Laboratory Manual on Biological Anthropology-Anthropometry, Kamla Raj Enterprises, New Delhi, India, 1968.

[8] World Health Organization, "Physical status: the use and interpretation of anthropometry," Tech. Rep. 854, World Health Organization, Geneva, Switzerland, 1995.

[9] T. J. Cole, K. M. Flegal, D. Nicholls, and A. A. Jackson, "Body mass index cut offs to define thinness in children and adolescents: International survey," British Medical Journal, vol. 335, no. 7612, pp. 194-197, 2007.

[10] T. J. Cole, M. C. Bellizzi, K. M. Flegal, and W. H. Dietz, "Establishing a standard definition for child overweight and obesity worldwide: international survey," The British Medical Journal, vol. 320, no. 7244, pp. 1240-1243, 2000.

[11] D. L. Pelletier and E. A. Frongillo, "Changes in child survival are strongly associated with changes in malnutrition in developing countries," Journal of Nutrition, vol. 133, no. 1, pp. 107-119, 2003.

[12] L. H. Allen, "Causes of nutrition-related public health problems of preschool children: available diet," Journal of Pediatric Gastroenterology and Nutrition, vol. 43, supplement 3, pp. 8-12, 2006.
[13] P. J. McGauhey, B. Starfield, C. Alexander, and M. E. Ensminger, "Social environment and vulnerability of low birth weight children: a social-epidemiological perspective," Pediatrics, vol. 88, no. 5, pp. 943-953, 1991.

[14] V. C. McLoyd, "Socioeconomic disadvantages and child development," American Psychologist, vol. 53, no. 2, pp. 185-204, 1998.

[15] R. H. Bradley and R. F. Corwyn, "Socioeconomic status and child development," Annual Review of Psychology, vol. 53, pp. 371-399, 2002.

[16] S. Das and K. Bose, "Prevalence of thinness among santal preschool children using new bodymass index cut-off points," Journal of Anthropology, pp. 1-4, 2011. 

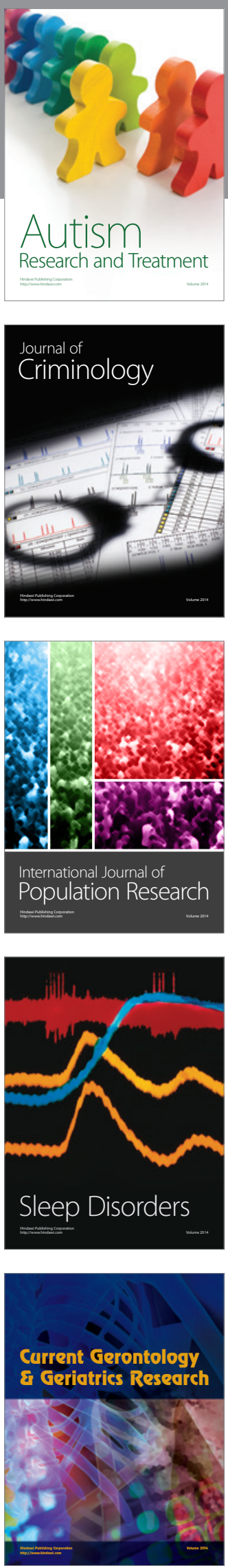
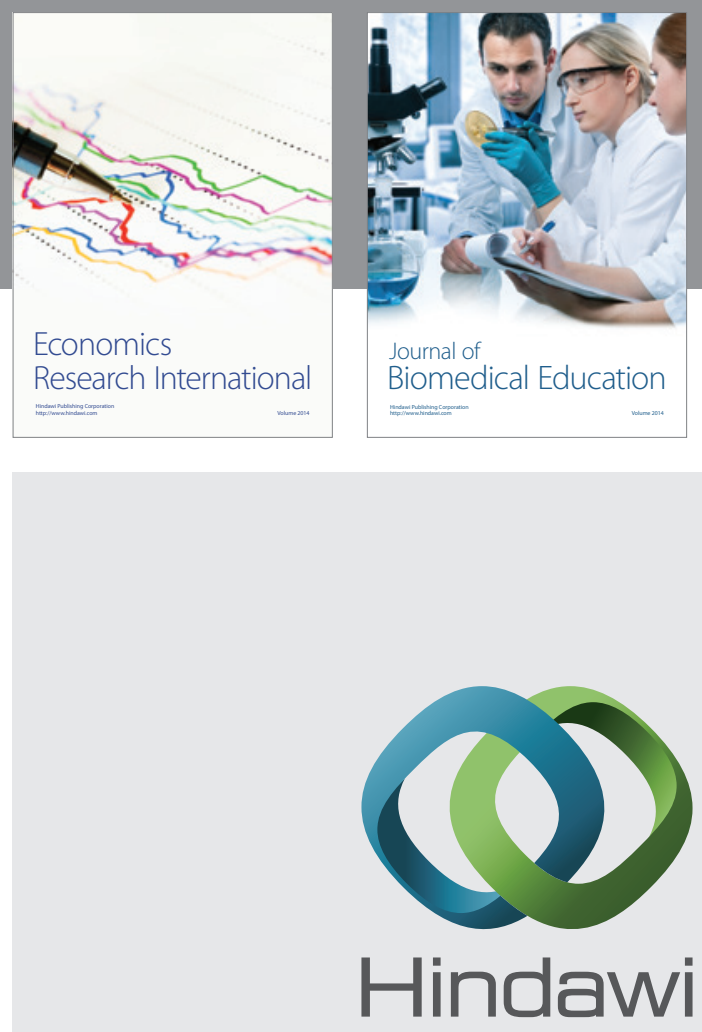

Submit your manuscripts at

http://www.hindawi.com
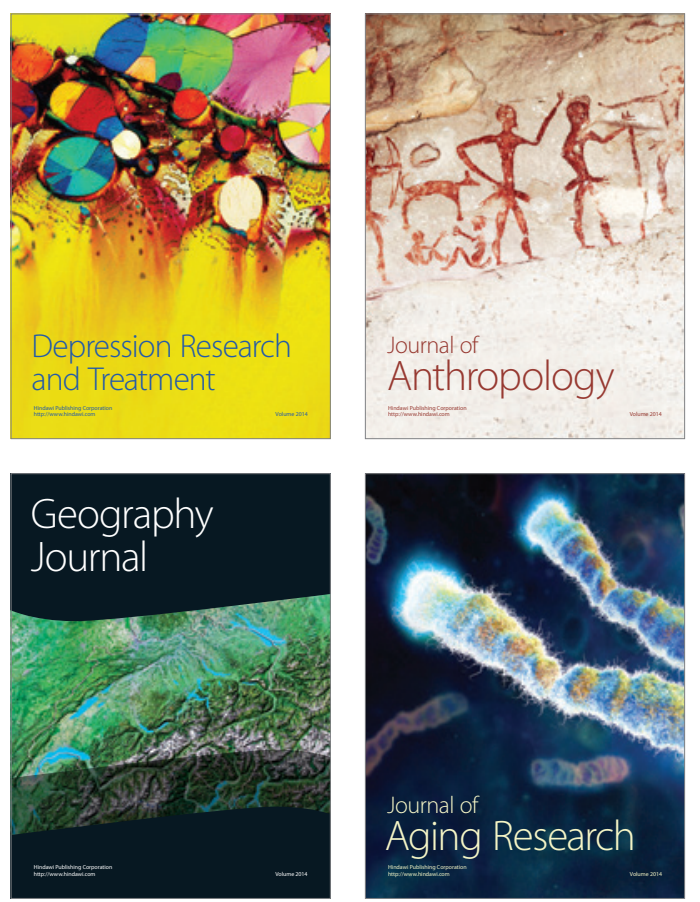
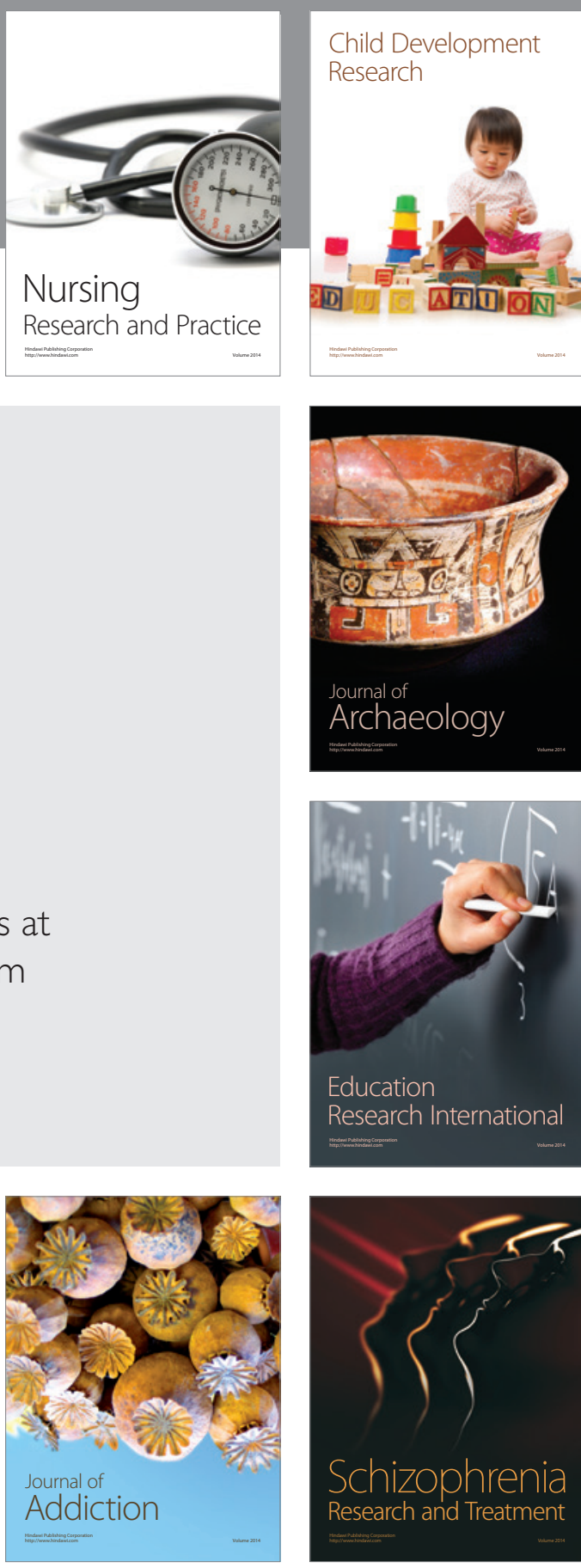

(D)
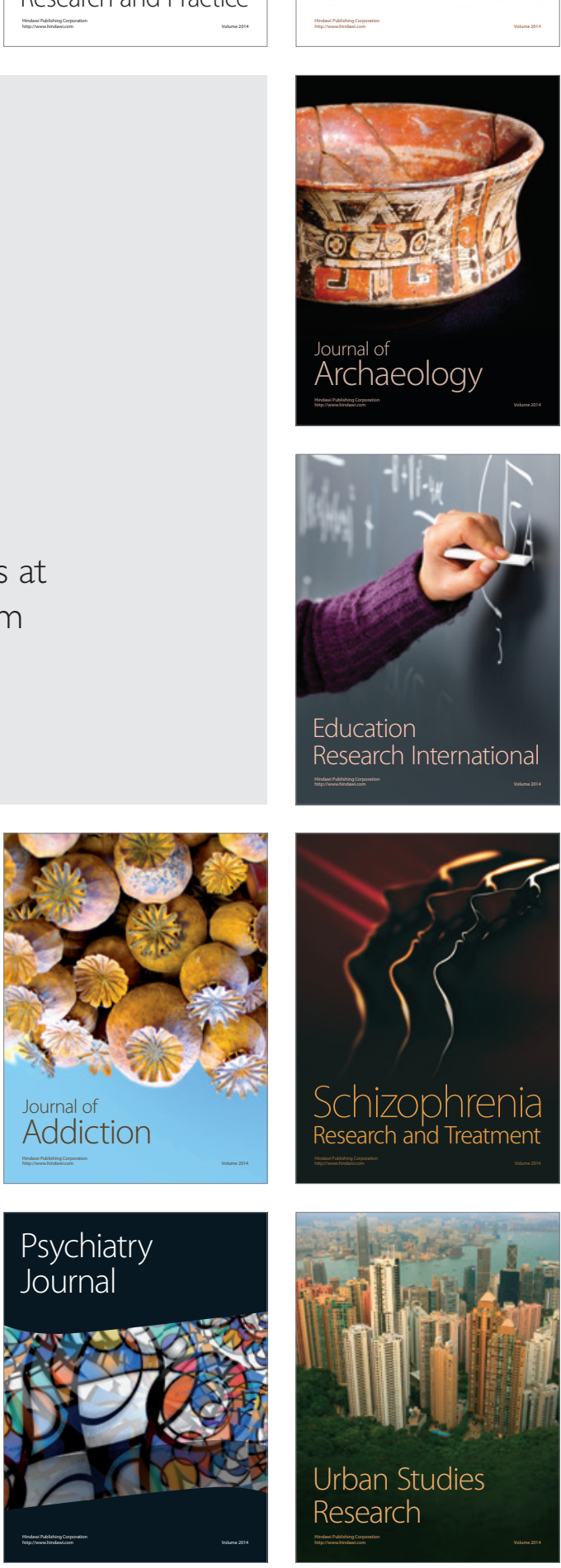